Bulletin be utilised more strategically to advance the aims of public health in NSW, for example by leading debate and discussion in relation to the more complex and emerging public health issues.

\section{CONCLUSION}

Overall, the findings of the review were positive and there was unanimous support for the Bulletin's continued publication. The review and its recommendations present an opportunity for further development of the Bulletin to ensure that it remains relevant and useful to the field.

The aim of the Bulletin is to publish population health data and peer-reviewed information to support public health action in NSW. As public health develops in NSW and the structures through which it is delivered changes, so the Bulletin should change to ensure that it remains relevant and useful.

\section{ACKNOWLEDGEMENTS}

The authors acknowledge the assistance of the members of the Review Advisory Group: Shelley Bowen, Anthony Brown, Kim Browne, Jeremy McAnulty and Peter Sainsbury.

\section{REFERENCES}

1. Jacq Hackett. Final Report: Review of the NSW Public Health Bulletin. Jacq Hackett Consulting: unpublished report, July 2005. 중

\title{
RESULTS FROM THE 2000 FAX-BACK SURVEY TO READERS ABOUT THE NSW PUBLIC HEALTH BULLETIN
}

\section{Belinda G. O’Sullivan \\ Public Health Training and Development Branch NSW Department of Health}

\section{Lynne Madden}

Editor, NSW Public Health Bulletin

NSW Department of Health

\section{ABSTRACT}

Publications must regularly reflect on their performance to ensure that they remain relevant to their readership and are fulfilling their objectives. In 2000 the 'NSW Public Health Bulletin Discussion Paper 2000'was released, with recommendations regarding all aspects of the Bulletin content, distribution and editorial management. A copy was sent to 1200 people with a fax-back survey seeking general feedback on the Bulletin and the recommendations. There was a response rate of 11 per cent. The survey identified broad support for the Bulletin and the recommendations. Findings included strong support for encouraging electronic access but maintaining the distribution of the printed copy. Subsequent changes to production of the Bulletin have included expanding the number of reviewers of articles and making improvements to the website.

In 1990 the NSW Public Health Bulletin was established to disseminate information among the newly formed public health infrastructure of the NSW health system and to provide regular feedback to practitioners on notifiable conditions, in particular communicable diseases. It has been in continuous publication since then, providing readers with free access to population health data and peer-reviewed information to support public health action in NSW.

The 'NSW Public Health Bulletin Discussion Paper 2000' was released in November 2000. It described the purpose of the Bulletin and the production process. It also recommended future directions in all aspects of the Bulletin's functions, including the aims and objectives, intended readership and distribution, content and style, peer-review processes, archiving, and editorial management. The Discussion Paper was released to stimulate a broad discussion and encourage comment to ensure that the Bulletin remained a useful tool for the NSW public health workforce. It was published as a Bulletin supplement. To encourage feedback about the Discussion Paper's recommendations a survey was conducted.

\section{METHODS}

A one-page fax-back survey and a copy of the Bulletin Discussion Paper, accompanied by a covering letter from the Chief Health Officer of NSW inviting participation in the survey, was mailed to a purposeful sample of 1200 people in NSW in December 2000. The sample was based upon the standard distribution list used for policies and publications within the NSW health system but enhanced to ensure thorough coverage of the structures responsible for the delivery of public health functions. This group was further expanded to include members of the Bulletin's Editorial Advisory Committee, authors published in the previous two years and peer reviewers or guest editors. Although the Bulletin's distribution included a small 
international readership, none of these readers were included. No reminder was sent to those who failed to reply.

The survey was in two parts. The first part asked respondents to identify their current job title and then sought 'yes' or 'no' responses about how they accessed the Bulletin, whether they used the index and if they had ever published in the Bulletin. The second part asked seven closed questions (again seeking 'yes' or 'no' responses) regarding respondents' support for the various recommendations made in the Discussion Paper. Open-ended responses were sought from those who did not support a recommendation. Simple frequencies were calculated for the responses to the closed questions and the open-ended responses were analysed for themes.

\section{RESULTS}

There were 128 responses: an 11 per cent response rate. Most originated from area health services (63 per cent); the remainder were mainly from the NSW Department of Health or the academic sector (Table 1). Respondents from area health services included 37 per cent from population health (divisions of population health and public health units), 21 per cent from administration (chief executive officers and health service managers) and five per cent from clinical areas.

While most respondents received the printed version of the Bulletin, approximately 40 per cent accessed the Bulletin via the web (Table 2). A similar proportion reported using the index. Approximately one third of respondents had published in the Bulletin.
Almost all respondents (97 per cent) supported the aims and objectives of the Bulletin as outlined in the Discussion Paper. Ninety-four per cent of respondents supported the recommendations that the Bulletin remain a peerreviewed publication of 16-24 pages in length. Nineteen comments were offered in response to this question: eight suggested a higher standard of peer-review be adopted, using two reviewers for papers rather than one, and one suggested that indexing with Medline be sought. Several people commented that an important role of the Bulletin is providing current information and acting as a means of communication for the workforce. They expressed concern that all content might become restricted to material that is peer-reviewed. Five people commented on the length of the publication, observing that 24 pages or shorter was a good length. One person suggested that the appearance was tired.

Eighty-nine per cent of respondents agreed that the readership should be encouraged to access the Bulletin through the Internet on the NSW Department of Health website. However, twenty-six of these respondents commented on the value of the printed copy, noting that a print version was needed for the foreseeable future and that access should not be restricted to the web version. The commonly cited reason was that not everyone has access to computers or to the web. This included many general practitioners, workers in early childhood centres and rural workers. Other reasons included: the time required to access and read a document on-line; that the printed version was quicker to read and; that some people had difficulty

\section{TABLE 1}

\section{LOCATION AND PROFESSIONAL BACKGROUND OF RESPONDENTS}

\begin{tabular}{|c|c|c|}
\hline LOCATION (AND PROFESSION) & $\mathbf{n}$ & $\%$ \\
\hline \multicolumn{3}{|l|}{$\begin{array}{l}\text { AREA HEALTH SERVICE } \\
\text { Population Health }\end{array}$} \\
\hline Public health units (directors, communicable disease nurses) & 11 & 9 \\
\hline Population health and planning divisions & 7 & 6 \\
\hline $\begin{array}{l}\text { Other population health workers (directors of mental health or sexual health, coordinator multicultural health, } \\
\text { community paediatrician, women's health, director drug and alcohol, health promotion unit, population health } \\
\text { statistician) }\end{array}$ & 12 & 9 \\
\hline Community health (managers or nurses) & 8 & 6 \\
\hline Early childhood nurses & 9 & 7 \\
\hline \multicolumn{3}{|l|}{ Administration } \\
\hline $\begin{array}{l}\text { Area hospital executive / managers (health service managers, chief executive officers, area health service board } \\
\text { members, human resource managers, director medical services, manager nursing services, director of nursing) }\end{array}$ & 27 & 21 \\
\hline \multicolumn{3}{|l|}{ Clinical } \\
\hline Clinical worker / specialist / manager or coordinator / Division of GPs & 6 & 5 \\
\hline \multicolumn{3}{|l|}{ NSW DEPARTMENT OF HEALTH } \\
\hline $\begin{array}{l}\text { Departmental managers (epidemiology, policy, communicable diseases, nursing, environmental health, oral health, } \\
\text { health promotion, health service planning, data and evaluation, public affairs) }\end{array}$ & 22 & 17 \\
\hline \multicolumn{3}{|l|}{ OTHER AREAS } \\
\hline Academic & 13 & 10 \\
\hline Others & 8 & 6 \\
\hline NOT STATED & 5 & 4 \\
\hline TOTAL & 128 & 100 \\
\hline
\end{tabular}


TABLE 2

ACCESS TO AND USE OF BULLETIN, AND HISTORY OF PUBLISHING IN THE BULLETIN $(\mathrm{N}=128)$

\begin{tabular}{|lcccccc}
\hline Bulletin access and use & Yes & $\%$ & No & No & \% \\
\hline Receives printed version & 104 & 81 & 22 & 17 & 2 \\
Accesses Bulletin through web & 53 & 41 & 69 & 54 & 5 \\
Uses the index & 55 & 43 & 68 & 53 & 5 \\
Ever published in Bulletin & 38 & 30 & 83 & 65 \\
\hline
\end{tabular}

negotiating information through the web. Many commented that they used both formats but for different purposes. Eight people suggested ways for improving the ease of access to and look of the Bulletin's web site.

Nearly all respondents (97 per cent) agreed they would like to see new types of regular features in the Bulletin. Ten comments were offered, including two suggestions for new areas: mental health and developments in vaccines.

Regarding the recommendation that there be an annual review of the Editorial Advisory Committee, 84 per cent of respondents agreed. However, of the 24 comments received, 20 suggested that annual review was too frequent and that a longer term was necessary. Two to three years was the common period suggested; more frequent review was considered potentially destabilising to the work of the committee. Rotating membership was suggested, as was inclusion of general practitioner representation.

Seven additional comments were received with the survey sheet. These covered a variety of issues including the need to keep the presentation dynamic and the importance of design to assist with presentation.

\section{DISCUSSION}

There was a positive response to the Bulletin and to the recommendations presented in the Discussion Paper. Although the survey contained mainly closed questions, the number of helpful comments offered demonstrated an enthusiasm for the publication. The low response rate, however, makes it difficult to draw general conclusions about the views of the whole readership.

Despite the low response rate there were a relatively large number of responses from senior health managers who were responsible for the population health workforce, such as chief executive officers and directors of Divisions of Population Health. In addition approximately 30 per cent of all respondents had published in the Bulletin.

The low response rate compares with the response to general readership surveys for other subscription or free publications and a previous readership survey of the Bulletin. ${ }^{2}$ The Bulletin readership was first surveyed through a postal survey that was included as part of the February 1993 issue. There was an eight per cent response rate. ${ }^{3}$ Surveys that have achieved higher response rates have used smaller, targeted samples. ${ }^{4,5}$

Other possible explanations for the low response rate to the 2000 faxback survey were the use of a broad sampling frame and the design of the survey instrument. Several respondents offered the criticism that some questions on the survey explored multiple factors while allowing only a single closed response. The closed question format may have also stimulated the large amount of free text comment provided by respondents. Future Bulletin surveys should consider refining the methods to gain high quality feedback.

Following the survey the peer review process was strengthened; two reviewers have been used for each manuscript since 2001. However, not all material submitted to the Bulletin requires peer review as the Bulletin seeks to retain the balance between the role of a peer-reviewed journal and a source of timely information. Nearly half the respondents had accessed the Bulletin through the web, although at that time the site was not easy to navigate and only a PDF format was available. At the end of 2001 the Bulletin was also made available in HTML and the Bulletin home page was redesigned to make it easier to navigate and search. The Bulletin has remained available in printed format.

\section{ACKNOWLEDGEMENTS}

We gratefully acknowledge Allison Salmon who helped coordinate data collection for this survey.

\section{REFERENCES}

1. NSW Department of Health. NSW Public Health Bulletin Discussion Paper 2000. N S W Public Health Bull Suppl Nov 2000; 11, S3.

2. Litt IF. Hello out there! Results of the J.A.H. Readership Survey. J Adolesc Health 1997; 21(6): 353-4.

3. Public Health Bulletin Readership Survey. N SW Public Health Bull; 1993; 4(2): 23-4.

4. Wilkinson MJ, Rapley DM, Gadsby R, Cohen MA. Does the BJGP need more fizz and pop? - A Midland faculty readership survey? Br J Gen Pract 1997 Mar; 47(416): 145-9.

5. Lundberg GD, Paul MC and Fritz H. A comparison of the opinions of experts and readers as to what topics a general medical journal (JAMA) should address. JAMA July 15 1998; 280(3): 288-90. 